\title{
SPORMETRE
}

The Journal of Physical Education and Sport Sciences Beden Eğitimi ve Spor Bilimleri Dergisi

DOI: $10.33689 /$ spormetre.667859

\section{PROFESYONEL FUTBOLCULARDA ANTROPOMETRİK DEĞİŞKENLER, YAŞ VE FUTBOLA KATILIM İLE GENU VARUM ARASINDAKİ İLİŞKİ}

\author{
Ali IŞIN ${ }^{1}\left(\mathbb{D}\right.$, Tuba MELEKOĞLU ${ }^{1 *}$ (i) \\ ${ }^{1}$ Akdeniz Üniversitesi, Spor Bilimleri Fakültesi, ANTALYA
}

\begin{abstract}
Öz: Genu varum diz dizilim bozukluklarından bir tanesidir ve futbolcularda yaygın olarak görülmektedir. Bu çalışmanın amacı erkek futbolcularda antropometrik değişkenler, yaş ve futbola katılım yılı ile genu varum arasındaki ilişkiyi incelemektir. Çalışmaya 17-31 yaş arası 117 erkek profesyonel futbolcu katılmıştır. Gönüllülerin boy uzunlukları, vücut ağırlıkları, vücut yağ yüzdeleri, vücut kütle indeksleri (VKİ) ve interkondiler mesafe (ICd) değerleri ölçülmüştür. Analizlerde SPSS 23 programı kullanılmıştır. Tüm veriler minimum (min), maksimum (max) ve ortalama \pm standart sapma (ort \pm Std) şeklinde sunulmuştur. Veriler arasındaki ilişki Pearson korelasyonu ile incelenmiştir. Vücut kompozisyonu ve genu varum değeri arasındaki ilişki incelendiğinde, ICd ile yaş $(\mathrm{p}<0.01)$ ve futbola katılım $(\mathrm{p}<0.001)$ arasında pozitif, ICd ile vücut yağ yüzdesi $(\mathrm{p}<0.05)$ arasında ise negatif korelasyon tespit edilmiştir. Bu çalışmanın sonucunda genu varum düzeyinin futbola katılım yılı ile arttığı tespit edilmiştir. Özellikle yaralanmalara karşı koruyucu önlem olarak, futbolcularda genu varum gelişiminin takip edilmesi ve gerekli düzeltici önlemlerin alınması önerilmektedir.
\end{abstract}

Anahtar Kelimeler: Futbol, genu varum, interkondiler mesafe, diz dizilimi

\section{THE RELATIONSHIP BETWEEN GENU VARUM AND ANTHROPOMETRICAL VARIABLES, AGE AND FOOTBALL PARTICIPATION IN PROFESSIONAL FOOTBALL PLAYERS}

\begin{abstract}
Genu varum is one of the knee alignment disorders and is common in soccer players. The aim of the study was to examine the relationship between genu varum and anthropometrical variables, age and football participation in professional football players. 117 male football players aged 17-31 years participated in the study. Volunteers' body height, body mass, body fat percentage, body mass index and intercondylar distance (ICd) was measured. SPSS 23 program was used for the analyzes. All data were presented as minimum (min), maximum (max) and mean \pm standard deviation (ort \pm Std). The relationship between the data was examined by using Pearson correlation. A positive correlation was found between ICd and age ( $\mathrm{p}<0.01)$ as well as ICd and participation in football $(\mathrm{p}<0.001)$. There was a negative correlation between body fat percentage and ICd $(\mathrm{p}<0.05)$. The result of this study stated that the level of genu varum increases with the year of participation in football. As a preventive measure, especially against injuries, it is recommended to follow the development of genu varum in football players and take necessary corrective measures.
\end{abstract}

Key Words: Football, genu varum, intercondylar distance, knee alignment

\section{GİRiş}

Futbol, dünya çapında en fazla katılıma sahip ve en popüler spor branşıdır. Her spor branşında olduğu gibi futbolun da futbolcular üzerine olumlu ve olumsuz etkileri bulunmaktadır. $\mathrm{Bu}$ olumsuz etkilerin en başında futbolcularda yaralanmalar gelmektedir (Dahlström ve ark., 2012). Futbolun yaralanmalar açısından sonuçları ve bunların önlenmesi birçok araştırmaya konu olmuştur (Olsen ve ark., 2004). Futbolun ayaklarla oynanması ve alt ekstremiteye binen yükün fazla olması nedeniyle, yaralanmaların büyük çoğunluğu alt ekstremitede ve diz ekleminde gerçekleşmektedir (Espregueira-Mendes ve ark., 2017). Futbolda diz ekleminde yaralanma 
riskinin artmasına neden olan faktörler oyuncunun yaşı, bir önceki yaralanma geçmişi ve dizin ligament durumudur (Fuller ve ark., 2006). Dizin ligament durumunu etkileyen faktörler arasında genu varum, genu valgum ve genu recurvatum gibi dizin dizilim bozuklukları gösterilmektedir (Işın, 2017).

Genu varum, diz ekleminin varus açısal deformitesidir (Rerucha ve ark., 2017; Rezende ve ark., 2011) ve futbolcular arasında en sik görülen diz dizilim bozukluğudur (Işın, 2017; Melekoğlu ve Işın, 2019). Genu varum özellikle interkondiler mesafeyi arttırarak, tibiofemoral açının değişmesine neden olur (Cheema ve ark., 2003). Yeni doğanlarda ve bebeklerde fizyolojik olarak kabul edilir ve 12 aya kadar en üst limitlere ulaşır. Normal büyüme sırasında, tibiofemoral açı 18 ila 24 ay arasında sıfıra ulaşır, daha sonra fizyolojik bir genu valgum haline gelir ve sonunda 7 yaşında yetişkin konfigürasyonuna ulaşır (Espandar ve ark., 2010).

Futbolcularda genu varumun diz osteoartritinin ilerlemesini hızlandırdığına dair güçlü kanıtlar bulunmaktadır (Cheema ve ark., 2003). Hatta diz osteoartritinin ilk başlangıcı için genu varumun bağımsız bir risk faktörü olması oldukça muhtemeldir (Tetsworth ve Paley, 1994). Hem profesyonel hem de amatör sporcuların, ileri yıllarda osteoartrit prevalansının yüksek olduğu bildirilmiştir (Driban ve ark., 2017; Higano ve ark., 2016). Genel popülasyonda, birçok faktör osteoartritin oluşumuna katkıda bulunmasına rağmen (Chaganti ve Lane, 2011; Fukaya ve ark., 2015), elit sporcularda, spora özgü zorlama ve yaralanmalar önemli bir rol oynar (Petrillo ve ark., 2018). Bu yaralanma ve zorlamaların eski profesyonel futbolcularda özellikle osteoartritin artmasının yanı sıra, genu varum insidansını da arttırdığ bulunmuştur (Arliani ve ark., 2014). Yüksek şiddetteki futbol antrenmanlarının eklemler üzerine uyguladığı yüksek stres ve gerginliğin, özellikle ergen ve adölesanlarda diz dizilimi bozarak, genu varuma neden olabileceği öngörülmektedir (Chantraine, 1985; Cheema ve ark., 2003).

Genu varum oluşumu; gelişimsel eğilme, doğuştan eğilme, tibia vara (Blount hastalığı), nörofibromatozis, raşitizm, osteogenezis imperfekta, kamptomelik displazi, akondroplazi ve hatta yoğun egzersiz gibi birçok faktörden kaynaklanmaktadır (Cheema ve ark., 2003; Espandar ve ark., 2010; Sass ve Hassan, 2003; Shim ve ark., 1997). Bununla birlikte yaş, cinsiyet, etnik faktörler, vücut ağırlığı, beslenme, çevre ve antrenman gibi birçok faktör genu varumu etkileyebilir (Cheng ve ark., 1991). Shohat ve ark. (2018) VKI'nin artmasiyla genu varum insidansının azaldığ 1 ve genu valgum insidansının arttığını bildirmişlerdir. Bu sonuç genu varum ve VKİ arasında ters bir korelasyonun yanı sıra genu valgum ve VKİ arasında pozitif bir korelasyon olduğunu göstermektedir. Bununla birlikte erkeklerin genu varum insidansının kadınlara kıyasla daha fazla olduğu tespit edilmiştir (Shohat ve ark., 2018). Ayrıca, ergen ve adölesan futbolcularda genu varum ile yaş, boy uzunluğu, vücut ağırlığ 1 ve vücut kütle indeksi arasında pozitif ilişkili olduğunu bildirmiştir. Futbolcularda antrenmana katılım yılının artmasıyla genu varumun da arttığı tespit edilmiştir (Asadi ve ark., 2015; Işın, 2017; Rezende ve ark., 2011).

Araştırmalar çoğunlukla 18 yaşından küçük futbolcularda genu varum insidansına odaklanmıştır. Bununla birlikte, futbol oynayan ve oynamayanlar arasındaki genu varum düzeyleri arasındaki farklılıklar araştırılmıştır (Asadi ve ark., 2015; Işın, 2017; Witvrouw ve ark., 2009). Bu çalışmalar özellikle futbol antrenmanlarına katılım ile genu varum arasında bir ilişki olduğunu göstermiş ve futbol oynamayan akranlarına kıyasla futbol oynayanlarda daha yüksek genu varum düzeyleri bildirmiştir (Asadi ve ark., 2015; Işın, 2017; Witvrouw ve ark., 2009). Ayrıca, futbolu bırakan futbolcuların \%73'ünün genu varuma sahip olduğu bildirmiştir (Chantraine, 1985). 
Literatürde koşma, pas atma, yer değiştirme, müdahale ve topa vurma (şut atma) gibi kapsamlı futbol uygulamaları çocuklarda genu varum gelişimine neden olabileceğine dair bulgular mevcuttur (Asadi ve ark., 2015). Bununla birlikte, antropometrik değişkenlerin özellikle çocuk ve ergenlerde diz dizilimi ile ilişkili olabileceği düşünülmektedir (Asadi ve ark., 2015; Işın, 2017; Rezende ve ark., 2011). Ancak, literatürde 18 yaşının üzerindeki futbolcularda genu varum ile yaş, boy uzunluğu, vücut ağırlığı ve vücut kütle indeksi arasındaki ilişki hakkında sınırlı bilgiler bulunmaktadır. Antropometrik değişkenler ile genu varum arasındaki ilişkinin bilinmesi, özellikle antropometrik açıdan daha büyük risk altında olan futbolcuların belirlenmesi, takibi ve koruyucu önlemlerin alınması açısından önem taşımaktadır. Bundan dolayı bu araştırmanın araştırmanın amacı profesyonel futbolcularda antropometrik değişkenler, yaş ve futbola katılım ile genu varum arasındaki ilişkinin incelenmesidir.

\section{YÖNTEM}

\section{Araştırma Grubu}

Araştırmaya haftada 3 gün futbol antrenmanlarına katılan en az 3 yıllık futbol antrenman geçmişine sahip, son bir yıl içerisinde diz sakatlığı, alt ekstremitelerde kas, kemik, bağ sakatlığ geçirmemiş 17-31 yaşları arası Ukrayna, Sırbistan, İsveç liglerinde oynayan 117 profesyonel erkek futbolcu katılmıştır. Tüm katılımcılara araştırma prosedürleri anlatılarak bilgilendirilmiş onam formları alınmıştır. Araştırma Akdeniz Üniversitesi Klinik Araştırmalar Etik Kurulu (1180-2019) tarafından onaylanmış ve Helsinki bildirgesine uygun olarak planlanmıştır. Araştırmaya katılan gönüllülerin futbol antrenman geçmişleri yıl olarak kaydedilmiştir.

\section{Veri Toplama Araçları}

Boy uzunluğu $(\mathrm{cm})$ stadiometre (Seca 213 , Almanya), vücut ağırlığ $(\mathrm{kg})$ ve vücut yağ yüzdesi (\%) biyoelektrik empedans cihazı (Tanita SC-330, Japonya) kullanılarak ölçülmüştür (Işın ve Melekoğlu 2019). Vücut kütle indeksi ( $\mathrm{kg} / \mathrm{m} 2)$ vücut ağırlığının boy uzunluğunun karesine bölünmesi ile hesaplanmıştır. İnterkondiler mesafe (ICd) ölçümü kondiller arasındaki mesafe olarak ölçülmüştür (Asadi ve ark. 2015; Rezende ve ark. 2011; Thijs ve ark. 2012). Ölçümler öncesinde her bir katılımcının kalça, diz ve ayak bileklerini doğal konumundayken diz ve ayak bileklerini birbirine yaklaştırması istenmiştir. Medial tibial malleolus kemikleri birbirine değdiği zaman medial femoral interkondiler arasındaki mesafe $0.01 \mathrm{~mm}$ hassasiyetinde kaliper (Gomax 150mm, Türkiye) kullanılarak milimetre $(\mathrm{mm})$ cinsinden ölçülmüştür (Melekoğlu ve Işın 2019; Rezende ve ark. 2011). ICd ölçümleri düz bir platform üzerinde ve çıplak ayak ile ölçülmüştür (Cheng ve ark. 1991).

\section{Verilerin Analizi}

Verilerin normal dağılıp dağılmadığını değerlendirmek için basıklık ve çarpıklık değerleri (Tabachnick ve Fidell 2013), histogram, normal Q-Q ve kutu grafiklerinin görsel değerlendirmesi, Shapiro-Wilk testi (Shapiro ve Wilk 1965) ve Levene testi (Levene 1960) kullanılmıştır. Tüm veriler ortalama \pm standart sapma (Ort \pm Std.), minimum (min) ve maksimum (mak) olarak sunulmuştur. Veriler arasındaki ilişki Pearson korelasyonu ile incelenmiştir. İstatistiksel analiz için SPSS (IBM Version 23, Armonk, NY, ABD) kullanılmış ve istatistiksel anlamlılık $\mathrm{p}<0.05, \mathrm{p}<0.01, \mathrm{p}<0.001$ olarak kabul edilmiştir.

\section{BULGULAR}

Katılımcıların yaş, boy uzunluğu, vücut ağırlığı, vücut yağ yüzdesi, VKİ, futbola katılım ve ICd değerleri Tablo 1'de gösterilmektedir. 
Tablo 1. Futbolcuların genu varum, antropometrik değişkenler, yaş ve futbola katılım değerleri

\begin{tabular}{lcc}
\hline Değişkenler (n:117) & Min - Max & Ort \pm Std. \\
\hline Yaş (yıl) & $17,0-30,99$ & $21,0 \pm 4,4$ \\
Boy Uzunluğu (cm) & $163,0-198,0$ & $180,0 \pm 7,4$ \\
Vücut Ă̆ırlığı (kg) & $46,6-98,7$ & $71,8 \pm 8,5$ \\
Vücut Yağ Yüzdesi (\%) & $3,0-16,2$ & $8,9 \pm 3,1$ \\
VKİ $\left(\mathrm{kg} / \mathrm{m}^{2}\right)$ & $16,1-27,0$ & $22,1 \pm 1,7$ \\
ICd $(\mathrm{mm})$ & $0,0-108,8$ & $39,7 \pm 21,3$ \\
Futbola Katılım (yıl) & $3,0-19,0$ & $8,2 \pm 4,5$
\end{tabular}

Min: Minimum, Max: Maksimum, Ort \pm Std.: Ortalama \pm Standart sapma VKİ: Vücut kütle indeksi, ICd: İnterkondiler mesafe

Genu varum ile antropometrik değişkenler, yaş ve futbola katılım yılı arasındaki ilişki Tablo 2'de verilmiştir.

Tablo 2. Genu varum ile antropometrik değişkenler, yaş ve futbola katılım yılı arasındaki ilişki

\begin{tabular}{|c|c|c|c|c|c|c|c|}
\hline \multicolumn{2}{|c|}{ Pearson K.K. (n:117) } & (2) & (3) & (4) & (5) & (6) & (7) \\
\hline ICd & (1) & ,245** & , 138 & 060 &,$- 201 *$ &,- 040 &, $360 * * *$ \\
\hline Yaş & (2) & 1 & ,330*** &, $426 * * *$ &,$- 521 * * *$ &, $281 * *$ &, $958 * * *$ \\
\hline Boy Uzunluğu & (3) & & 1 &, $764 * * *$ &,- 159 & 081 &, $347 * * *$ \\
\hline Vücut Ağırlığı & (4) & & & 1 & , 168 &, $702 * * *$ &, $407 * * *$ \\
\hline Vücut Yă̆ Yüzdesi & (5) & & & & 1 & ,443 &,$- 508 * * *$ \\
\hline VKİ & (6) & & & & & 1 & $235^{*}$ \\
\hline Futbola Katılım & (7) & & & & & & 1 \\
\hline
\end{tabular}

\section{TARTIŞMA VE SONUÇ}

Futbol ve genu varum arasındaki ilişki son yıllarda araştırmacıların odak noktası olmuştur (Asadi ve ark., 2015; Işın, 2017; Melekoğlu ve Işın, 2019; Rezende ve ark., 2011). Genu varum insidansının; yaş, vücut ağırlığı, metabolik bozukluklar, D vitamini eksikliği ve çevresel unsurlar dahil olmak üzere çeşitli faktörlerle ilişkili olduğu görülmektedir (Cheng ve ark., 1991; Witvrouw ve ark., 2009). Bununla birlikte, araştırmalar futbol oyunu esnasında alt ekstremiteye daha fazla yük binmesinden dolayı, diz diziliminin değiştiğini bildirmişlerdir (Witvrouw ve ark., 2009). Futbol oyunu esnasında sıç̧a kullanılan ani yön değişimleri, özellikle diz ekleminde mekanik zorlamalara neden olur ve ayrıca nöromüsküler yorgunluğun artmasıyla dinamik diz eklemi stabilizasyonu azalır. Bu mekanizmaların sonucu olarak da yaralanma riski $\operatorname{artar}$ (Besier ve ark., 2001).

Futbol uygulamaları esnasında kaslara, dokulara ve kemik üzerine gerçekleşen akut ve kronik yükler, özellikle patellofemoral eklem üzerine olumsuz etki edebilmektedir. Bu tekrarlayan yüklerin sonucu olarak genu varum insidansı artabilir (Braz ve Carvalho, 2010; Brouwer ve ark., 2007; Işı1n, 2017; Lewek ve ark., 2004; Nguyen ve ark., 2009; Witvrouw ve ark., 2009). Genu varum oluşumunu yapısal olarak etkileyen bileşenler kalça diz açısı, diz ekleminin yapısı 
ve tibiadır. Femurun tibia ile hizalanmasındaki bozukluk genu varuma neden olmakta ve sporcular için risk oluşturmaktadır. Bu durum diz ekleminin medial bölümleri üzerine anormal stres oluşturmaktadır. Bu da sporcuyu yaralanmalara daha açık hale getirmektedir (Neely 1998). Ayrıca genu varumda olduğu gibi, diz ekleminde gerçekleşen bu yapısal değişiklikler ve değişen plantar basınç dağılımı, özellikle iliotibial bant sendromu, kronik diz ağrısı ve osteoartrit gibi aşırı kullanıma bağlı yaralanmalara futbolcuları yatkınlaştırmaktadır (Braz ve Carvalho 2010). Ayrıca literatürde, genu varumun patellofemoral sendrom ve ön çapraz bağ yaralanmaları için bir risk faktörü olduğu da bildirilmiştir (Pappas ve Wong-Tom, 2012; Waryasz ve McDermott, 2008). Bu nedenle çeşitli çalışmalarda, özellikle futbolcularda görülen genu varum etyolojisi üzerine daha fazla çalışma yapılmasının gerektiği bildirilmiştir (Brouwer ve ark., 2007; Espandar ve ark., 2010; Greig, 2019; Jan van de Pol ve ark., 2009; Lewek ve ark., 2004).

$\mathrm{Bu}$ araştırmanın da amacı profesyonel futbolcularda antropometrik değişkenler, yaş ve futbola katılım ile genu varum arasındaki ilişkinin incelenmesidir. Bu amaç doğrultusunda 17-31 yaşları arası 117 erkek futbolcu araştırmaya dahil edilmiştir. Genu varum düzeyini belirlemek için interkondiler mesafe hesaplanmış ve futbola katılım yılı, yaş ve bazı antropometrik değişkenler ile ilişkisi incelenmiştir.

Araştırma sonucunda genu varum ile yaş arasında pozitif, vücut yağ yüzdesi arasında negatif korelasyon tespit edilmiştir. Her ne kadar araştırmamız sonucunda; boy uzunluğu, vücut ağırlığ ve VKİ değerleri ile genu varum arasında korelasyon tespit edilmese de literatürde pozitif korelasyon tespit eden çalışmalar bulunmaktadır (Asadi ve ark., 2015; Işın, 2017; Rezende ve ark., 2011). Işın (2017) futbolcularda genu varum ile yaş, boy uzunluğu, vücut ağırlığı ve VKİ ile pozitif yönde, vücut yağ yüzdesi ile negatif yönde korelasyon içinde olduğunu bildirmiştir. Benzer şekilde Asadi ve ark., (2015), genu varum ile futbolcuların boy uzunluğu, vücut ağırlığı, yaş ve VKİ değerleri arasında pozitif bir ilişki olduğunu rapor etmiştir. Ayrıca artan boy uzunluğu, vücut ağırlığı, yaş ve VKİ ile birlikte daha ciddi genu varum düzeylerinin görüldügüüü bildirmiştir. Rezende ve ark., (2011) tarafından genu varum ve yaş, boy uzunluğu, vücut ağırlığı ve VKİ düzeyleri arasında pozitif ve anlamlı ilişkiler bulunmuştur (Rezende ve ark., 2011). Bayraktar ve ark., (2004) futbolcularda tibiofemoral açı ile yaş arasında negatif bir korelasyon olduğunu bildirmiştir. Ayrıca Tarawneh ve ark., (2016) boyun uzamasıyla birlikte quadriceps açısının azaldığını rapor etmişken, Hann ve Foldspang (1997) antrenman ve yaşla birlikte quadriceps açılarının azaldığını bildirmiştir. Literatürde genu varum üzerine ve diz dizilimi üzerine yapılan bu araştırmaların sonucu olarak; boy uzunluğunun artması ve quadriceps kasının kuvvetlenmesiyle birlikte quadriceps açılarının azaldığı öngörülmektedir. Fakat ICd değerleri incelendiğinde ise futbolcularda özellikle futbola katılımla birlikte genu varum düzeyinin arttığı rapor edilmiştir (Asadi ve ark., 2015; Işın, 2017; Melekoğlu ve Işsin, 2019; Thijs ve ark., 2012; Witvrouw ve ark., 2009).

Mevcut araştırma sonucunda futbolcularda ICd değerinin 39,7 $\pm 21,3 \mathrm{~mm}$ olduğu ve yaşla birlikte ICd değerinin arttığı tespit edilmiştir. Işın (2017) yaş ortalamaları 14,76 $\pm 2,35$ olan futbolcularda ICd değerini 19,70 $\pm 18,01 \mathrm{~mm}$ olarak bildirmiştir. Melekoğlu ve Işın (2019) futbol oynama statülerine göre ICd değerlerini kıyaslamışlar ve elit düzeyde futbol oynayanların $(45,65 \pm 13,54 \mathrm{~mm})$, amatör düzeyde futbol oynayanlara $(28,84 \pm 14,61 \mathrm{~mm})$ kıyasla ICd değerlerinin istatistiksel olarak anlamı olarak daha yüksek olduğunu tespit etmişlerdir. Futbol oynayan ve oynamayan öğrencilerin alt ekstremite dizilim bozukluklarının karşılaştırıldığ gözlenmiş ve futbolcuların \%67,7'sinde genu varum bildirilmiştir (Rezende ve ark., 2011). Bununla birlikte bazı çalışmalar veteran futbolcularda yüksek genu varum insidansı 
bildirmişlerdir (Chantraine, 1985; Drawer ve Fuller, 2001). Benzer şekilde Chantraine ve ark., (1985) yoğun futbol antrenmanlarına katılım ile genu varum derecesinin arttırdığını bildirmiştir. Asadi ve ark., (2015) yaptığı çalışmada da futbola katılım yılı arttıkça genu varum insidansının ve derecesinin arttığ 1 rapor edilmiştir. $\mathrm{Bu}$ anlamda araştırma sonuçlarımız literatürle benzerlik göstermektedir. Yapılan istatistiksel değerlendirme sonucunda genu varum ile futbola katılım y1lı arasında pozitif korelasyon tespit edilmiştir.

$\mathrm{Bu}$ araştırmanın sınırlılıklarından birisi örneklem grubunu sadece profesyonel erkek futbolculardan oluşmasıdır. İstatistiksel açıdan yeterli sayıda kadın profesyonel futbolcuya ulaşılamadığı için araştırma sadece erkek futbolcular üzerine yapılmıştır. Bir diğer sınırlılık da farklı şiddet ve kapsamlardaki futbol uygulamalarına maruz kalan futbolcuların verilerinin değerlendirilememesidir. Araştırmaya Antalya'ya sezon hazırlık kampı için gelen ve Avrupa futbol liglerinde oynayan profesyonel futbolcular katılmıştır. Araştırmanın bir sınırlılığ da Avrupa' daki tüm ülkelerden futbolculara ulaşılamamış olmasıdır.

$\mathrm{Bu}$ araştırmanın sonucunda, genu varum ile yaş ve futbola katılım arasında pozitif, vücut yăg yüzdesi arasında negatif korelasyon tespit edilmiştir. Futbolcuların yaşları ilerledikçe futbola katılım yılları da artmakta ve bununla birlikte daha fazla antrenman yüküne maruz kalmaktadırlar. Bunun sonucu olarak da ilerleyen yaşla birlikte futbolcularda, genu varum düzeyi ve beraberinde yaralanma riski artmaktadır. Bu nedenle antrenörlerin ve futbol uygulamacılarının, oyuncularında genu varum oluşumunu takip etmeleri ve düzeltici önlemleri almaları önemlidir. $\mathrm{Bu}$ araştırma sadece profesyonel futbolcularda genu varum ile antropometrik değişkenler, yaş ve futbola katılım arasındaki ilişkiyi açıklamayı amaçlamıştır, gelecek çalışmaların kadınlar ve farklı düzeyde futbol geçmişine sahip futbolcular üzerine de (amatör, rekreatif ve futbolu bırakmış) yapılması önerilmektedir. Ayrıca futbolcularda genu varum etyolojisinin etnik köken açısından da incelenmesi literatüre önemli katkılar sağlayacağı düşünülmektedir.

\section{KAYNAKLAR}

Arliani G.G., Astur D.C., Yamada R.K.F., Yamada A.F., Miyashita G.K., Mandelbaum B., Cohen M. (2014). Early osteoarthritis and reduced quality of life after retirement in former professional soccer players. Clinics, 69(9), 589-94.

Asadi K., Mirbolook A., Heidarzadeh A., Kivi M.M., Meybodi M.K.E., Rad, M.R. (2015). Association of soccer and genu varum in adolescents. Trauma monthly, 20(2), 47-51.

Bayraktar B., Yucesir I., Ozturk A., Cakmak A. K., Taskara N., Kale A., Demiryurek, D., Bayramoglu A., Camlica H. (2004). Change of quadriceps angle values with age and activity. Saudi medical journal, 25(6), 756-760.

Besier T.F., Lloyd D.G., Cochrane J.L., Ackland T.R. (2001). External loading of the knee joint during running and cutting maneuvers. Medicine \& Science in Sports \& Exercise, 33(7), 1168-75.

Braz R.G., Carvalho G.A. (2010). Relationship between quadriceps angle (Q) and plantar pressure distribution in football players. Brazilian Journal of Physical Therapy, 14(4), 296-302.

Brouwer G.M., van Tol A.W., Bergink A.P., Belo J.N., Bernsen R.M., Reijman M., Pols H.A., Bierma-Zeinstra S.M. (2007). Association between valgus and varus alignment and the development and progression of radiographic osteoarthritis of the knee. Arthritis Rheumatol, 56(4), 1204-1211.

Chaganti R.K., Lane N.E. (2011). Risk factors for incident osteoarthritis of the hip and knee. Current reviews in musculoskeletal medicine, 4(3), 99.

Chantraine A. (1985). Knee joint in soccer players: osteoarthritis and axis deviation. Medicine and science in sports and exercise, 17(4), 434-439. 
Cheema J.I., Grissom L.E., Harcke H.T. (2003). Radiographic characteristics of lower-extremity bowing in children. Radiographics, 23(4), 871-880.

Cheng J.C., Chan P.S., Chiang S.C., Hui P.W. (1991). Angular and rotational profile of the lower limb in 2,630 Chinese children. Journal of pediatric orthopedics, 11(2), 154-161.

Dahlström Ö., Backe S., Ekberg J., Janson S., Timpka, T. (2012). Is “football for all” safe for all? Cross-sectional study of disparities as determinants of 1-year injury prevalence in youth football programs. PloS one, 7(8), 1-7

Drawer S., Fuller C. (2001). Propensity for osteoarthritis and lower limb joint pain in retired professional soccer players. British journal of sports medicine, 35(6), 402-408.

Driban J.B., Hootman J.M., Sitler M.R., Harris K.P., Cattano N.M. (2017). Is participation in certain sports associated with knee osteoarthritis? A systematic review. Journal of athletic training, 52(6), 497-506.

Espandar R., Mortazavi S.M.J., Baghdadi T. (2010). Angular deformities of the lower limb in children. Asian journal of sports medicine, 1(1), 46-53

Espregueira-Mendes J., van Dijk C.N., Neyret P., Cohen M., Della Villa S., Pereira H., Oliveira, J.M. (2017). Injuries and Health Problems in Football: Springer, 49-52.

Fukaya T., Mutsuzaki H., Wadano Y. (2015). Kinematic analysis of knee varus and rotation movements at the initial stance phase with severe osteoarthritis of the knee. The Knee, 22(3), 213-216.

Fuller C.W., Ekstrand J., Junge A., Andersen T.E., Bahr R., Dvorak J., . . Meeuwisse, W. H. (2006). Consensus statement on injury definitions and data collection procedures in studies of football (soccer) injuries. Scandinavian journal of medicine \& science in sports, 16(2), 83-92.

Greig M. (2019). Concurrent changes in eccentric hamstring strength and knee joint kinematics induced by soccerspecific fatigue. Physical Therapy in Sport, 37, 21-26.

Hahn T., Foldspang A. (1997). The Q angle and sport. Scandinavian journal of medicine \& science in sports, 7(1), 43-48.

Higano Y., Hayami T., Omori G., Koga Y., Endo K., Endo N. (2016). The varus alignment and morphologic alterations of proximal tibia affect the onset of medial knee osteoarthritis in rural Japanese women: Case control study from the longitudinal evaluation of Matsudai Knee Osteoarthritis Survey. Journal of Orthopaedic Science, $21(2), 166-171$

Işın A. (2017). Futbola katılımın genu varum üzerine etkisi. Yayımlanmış Yüksek Lisans tezi, Akdeniz Üniversitesi, Sağlık Bilimler Enstitüsü, Hareket ve Antrenman Anabilim Dalı Antalya.

Işın A., Melekoğlu T. (2019). Akut kuvvet antrenmanının biyoelektrik empedans ölçümleri üzerine etkileri. Cukurova Medical Journal, 44(1), 80-6.

Jan van de Pol G., Arnold M.P., Verdonschot N., van Kampen A. (2009). Varus alignment leads to increased forces in the anterior cruciate ligament. Am J Sports Med, 37(3), 481-487.

Levene H. (1960). Contributions to probability and statistics. Essays in honor of Harold Hotelling, 278-292.

Lewek M.D., Rudolph K.S., Snyder-Mackler L. (2004). Control of frontal plane knee laxity during gait in patients with medial compartment knee osteoarthritis. Osteoarthritis and Cartilage, 12(9), 745-751.

Melekoğlu T., Işın A. (2019). The Relationship Between Football Participation Level and Lower Leg Alignment in Youth Males: Genu Varum. Journal of Education and Training Studies, 7(2), 137-41.

Neely F.G. (1998). Biomechanical risk factors for exercise-related lower limb injuries. Sports medicine, 26(6), 395-413. 
Nguyen A.D., Boling M.C., Levine B., Shultz S.J. (2009). Relationships Between Lower Extremity Alignment and the Quadriceps Angle. Clin J Sport Med, 19(3), 201-206.

Olsen L., Scanlan A., MacKay M., Babul S., Reid D., Clark M., Raina P. (2004). Strategies for prevention of soccer related injuries: a systematic review. British journal of sports medicine, 38(1), 89-94.

Pappas E., Wong-Tom W.M. (2012). Prospective predictors of patellofemoral pain syndrome: a systematic review with meta-analysis. Sports Health, 4(2), 115-120.

Petrillo S., Papalia R., Maffulli N., Volpi P., Denaro V. (2018). Osteoarthritis of the hip and knee in former male professional soccer players. British medical bulletin, 125(1), 121-130.

Rerucha C.M., Dickison C., Baird D.C. (2017). Lower extremity abnormalities in children. American family physician, 96(4), 226-233.

Rezende L.F.M.d., Santos M.d., Araújo T.L., Matsudo V.K.R. (2011). Does soccer practice stress the degrees of Genu Varo? Revista Brasileira de medicina do esporte, 17(5), 329-33.

Sass P., Hassan, G. (2003). Lower extremity abnormalities in children. American family physician, 68(3), 461468.

Shapiro S.S., Wilk M. B. (1965). An analysis of variance test for normality (complete samples). Biometrika, 52(3/4), 591-611.

Shim J.S., Kim H.T., Mubarak S.J., Wenger D. R. (1997). Genu valgum in children with coxa vara resulting from hip disease. Journal of Pediatric Orthopaedics, 17(2), 225-229.

Shohat N., Machluf Y., Farkash R., Finestone A. S., Chaiter, Y. (2018). Clinical knee alignment among adolescents and association with body mass index: A large prevalence study. The Israel Medical Association journal: IMAJ, 20(2), 75 .

Tabachnick B.G., Fidell L.S. (2013). Using multivariate statistics (6 th ed.). Pearson.

Tarawneh I., AL-Ajoulin O., Alkhawaldah A., Kalbouneh H., Hadidi M. (2016). Normal values of Quadriceps angle and its correlation with anthropometric measures in a group of Jordanians. Journal of the Royal Medical Services, 102(3396), 1-6.

Tetsworth K., Paley D. (1994). Malalignment and degenerative arthropathy. Orthopedic Clinics of North America, 25(3), 367-378.

Thijs Y., Bellemans J., Rombaut L., Witvrouw E. (2012). Is high-impact sports participation associated with bowlegs in adolescent boys? Medicine and science in sports and exercise, 44(6), 993-998.

Waryasz G.R., McDermott A.Y. (2008). Patellofemoral pain syndrome (PFPS): a systematic review of anatomy and potential risk factors. Dynamic medicine, $7(1), 9$.

Witvrouw E., Danneels L., Thijs Y., Cambier D., Bellemans J. (2009). Does soccer participation lead to genu varum? Knee surgery, sports traumatology, arthroscopy, 17(4), 422-427. 